\title{
Globe
}

Revue internationale d'études québécoises

\section{Yvan Lamonde, La modernité au Québec. La Crise de l'homme et de l'esprit, 1929-1939, Montréal, Fides, 2011}

\section{Éric Desautels}

Volume 15, numéro 1-2, 2012

URI : https://id.erudit.org/iderudit/1014650ar

DOI : https://doi.org/10.7202/1014650ar

Aller au sommaire du numéro

Éditeur(s)

Globe, Revue internationale d'études québécoises

ISSN

1481-5869 (imprimé)

1923-8231 (numérique)

Découvrir la revue

Citer ce compte rendu

Desautels, É. (2012). Compte rendu de [Yvan Lamonde, La modernité au Québec. La Crise de l'homme et de l'esprit, 1929-1939, Montréal, Fides, 2011]. Globe,

15(1-2), 374-376. https://doi.org/10.7202/1014650ar d'utilisation que vous pouvez consulter en ligne.

https://apropos.erudit.org/fr/usagers/politique-dutilisation/ 


\section{Yvan Lamonde \\ La modernité au Québec. La Crise de l'homme \\ et de l'esprit, 1929-1939, Montréal, Fides, 2011.}

Recensant l'histoire intellectuelle canadienne-française de la crise des années 1930, Yvan Lamonde nous rappelle très bien d'entrée de jeu ce que signifie la modernité. Évoquant le poète Hector de Saint-Denys Garneau, qui fut une figure marquante de la modernité à l'époque, Lamonde souligne que "si la modernisation est un rapport nouveau à l'espace et aux objets, la modernité réfère avant tout au temps, renvoie d'abord à une conscience générationnelle» (p. 9). La modernité ne s'applique pas uniquement aux faits matériels, financiers, sociétaux ou organisationnels (espaces et objets), mais aussi à la temporalité et aux idées. Pour les jeunes intellectuels des années 1930, il s'agissait "d'être de son temps " : «Il faut être de son temps même si ce sont des temps difficiles, il faut trouver des valeurs nouvelles et, surtout, savoir comment ces valeurs nouvelles peuvent prendre racine» (p. 295).

Les quatre premiers chapitres de l'ouvrage recensent l'émergence de cette pensée nouvelle, d'un renouveau parmi les jeunes générations de catholiques canadiens-français. Passant de l'Association catholique de la jeunesse canadienne-française (ACJC) à l'Action catholique spécialisée et la revue La Relève, ainsi que par les jeunes intellectuels Guy Frégault, JeanCharles Harvey, Louis Francoeur et François Hertel, Lamonde explore les réseaux de la jeunesse catholique des années de la crise. Il décrit leur réaction face au "progrès » émergent et à l'ordre établi. Cette crise des années 1930 dépassait le strict cadre économique et social : elle atteignait également les sphères religieuse et spirituelle, comme en témoigne la pensée nationaliste du chanoine Lionel Groulx, la crise de l'Action française et l'influence du personnalisme de Maritain.

L'auteur présente ensuite les dynamiques sociales qui ont affecté cette génération de contestataires des structures et des mœurs politiques et religieuses. Au début des années 1930, le nationalisme créait beaucoup d'espoir parmi les jeunes intellectuels : un nationalisme en réaction à la crise économique, au libéralisme du gouvernement Taschereau et à la pensée nationaliste dépassée d'Henri Bourassa. Les membres du mouvement JeuneCanada voulaient devenir «maître chez soi » devant les trusts et la domination juive et anglophone au Québec dans le secteur économique. Une effervescence nationaliste et même indépendantiste ou séparatiste émergeait 
alors et amenait débats, tensions et affinités chez les intellectuels de l'époque, parmi lesquels Lionel Groulx, André Laurendeau et Saint-Denys Garneau étaient des figures de proue.

Dans ce contexte de renouveau nationaliste et spirituel, le chapitre 9 relève l'ascension au pouvoir de Maurice Duplessis et l'espoir des jeunes intellectuels. Misant sur l'appui de Paul Gouin et de son Action libérale nationale, Duplessis a mené une campagne victorieuse en jouant sur la fibre nationaliste. Mais, selon Lionel Groulx, le nationalisme de Duplessis a rapidement laissé place à une déception aux effets néfastes. Ce fut l'échec, en 1936, d'un projet national qui était en gestation depuis 1932 au sein d'une partie de la jeunesse canadienne-française.

L'année 1937 constitue une série de tournants dans le discours et la pensée de plusieurs intellectuels ou organisations jeunesse. Cette année 1937 représente la «ligne de partage des eaux entre tradition et modernité», soutient Lamonde (p. 133). Le groupe indépendantiste Jeunesses Patriotes avec entre autres les frères O'Leary (chapitre 10), la pensée séparatiste et fasciste de Paul Bouchard dans La Nation (chapitre 11), le retour au Québec d'André Laurendeau qui implique une nouvelle voie d'engagement pour l'Action nationale (chapitre 12), ainsi que la pensée non conformiste, antinationaliste et anticlérical de Jean-Charles Harvey dans le quotidien $L e$ Jour (chapitre 13) représentent quelques-uns des éléments retenus par l'auteur pour illustrer ces tournants.

Ces tendances et ces dynamiques diverses révèlent non seulement une effervescence des idées en réaction au conservatisme, au capitalisme antisyndical et à la déception du nationalisme de Maurice Duplessis, mais elles proposent aussi différentes solutions pour sortir de la crise des années 1930 (chapitre 14). Tandis que le corporatisme pénètre les cercles catholiques, le communisme et le libéralisme étaient fortement contestés ou remis en question. Différentes voies étaient alors envisagées parmi les intellectuels de l'époque afin de sortir de la crise. Il s'agit des « $5 \mathrm{C}$ » que Lamonde évoque et reprend tout au long de son ouvrage : communisme, corporatisme, capitalisme, coopératisme et colonisation (p. 16 et 209).

Par exemple, le corporatisme de Guy Frégault offrait l'intégration d'une autonomie personnelle, inspirée du personnalisme français. En fait, un regard nouveau se posait sur la France catholique contemporaine de l'époque où les représentations traditionnelles éclataient. Daniel-Rops, Jacques Maritain, Emmanuel Mounier, Alexandre Marc et Nicolas Berdiaef tentaient de vivre leur catholicisme autrement et ils en trouvaient des échos au Canada français. 
Si plusieurs positions étaient adoptées en regard de la pensée et la culture françaises, l'influence des États-Unis était plus limitée. Les nationalistes demeuraient critiques face à l'américanisation et au matérialisme américain. Malgré tout, Marie Victorin, Alfred Desrochers, Pierre Dansereau et François Hertel découvraient quelques affinités avec nos voisins du sud. Cette époque marque le passage - primordial pour comprendre cette période de l'histoire - de l'esprit de parti au "parti de l'esprit ", c'est-à-dire que tout mouvement ou action devait se situer au-dessus de tout parti. Elle est aussi marquée par la peur, le sentiment d'infériorité qui prenait racine dans le discours populaire. L'âme moderne émergeait et naviguait à travers les incertitudes et les visions nouvelles d'une jeunesse qui cherchait à se redéfinir, à prendre conscience d'un sujet qui recherche l'universel ou ce qui, dans la crise, est commun à l'humanité. Cette recherche de l'universel causait de nombreuses tensions chez les intellectuels des années 1930, au croisement de l'universel, du national et du culturel. Il s'agissait, pour les jeunes intellectuels canadiens-français, de se réapproprier et de réactualiser le passé : une "continuation active du passé » selon la perspective d'André Laurendeau (p. 256).

L'ouvrage recense donc les réseaux intellectuels des années 1930 en décrivant les tensions et les affinités entre différentes pensées, idéologies et conceptions de l'État qui marquent l'émergence d'une pensée moderne, d'une pensée visant le «progrès » de la société canadienne-française. Les interactions entre les sphères religieuse, politique, culturelle et artistique sont particulièrement mises en valeur. Ce livre permet de retracer les différentes voies d'engagement empruntées par les jeunes intellectuels canadiensfrançais en réaction à la crise plurielle (économique, sociale, religieuse, culturelle, spirituelle) des années 1930. Ce regard historique sur le Québec des années 1930 est d'une grande actualité. L'effervescence intellectuelle, la volonté de se réapproprier collectivement les richesses du territoire québécois, le refus du conformisme, la réponse de la population aux scandales liés au gouvernement libéral de Louis-Alexandre Taschereau ainsi que le développement d'une pensée critique entre 1929 et 1939 sont des éléments qui concernent également l'histoire récente du Québec.

Éric Desautels Université Concordia 